\title{
AS LUTAS DA HISTÓRIA IMEDIATA: PARA QUEM SERVE A VERDADE HISTÓRICA?
}

\author{
Lucas Patschiki ${ }^{1}$. \\ Universidade Estadual do Oeste do Paraná \\ UNIOESTE
}

\section{RESUMO}

Neste artigo iremos abordar algumas argumentações historiográficas de origem francesa que, tomadas como problemas teórico-metodológicos, visam impedir, dificultar ou limitar a análise pelos historiadores dos processos vividos, a prática da história imediata. Iremos compreender estas questões através das funções sociais e políticas que a verdade histórica (construída segundo um método, uma base teórica metodológica aprimorada e confirmada pela prática histórica) cumpre nas lutas sociais do presente, a história como possibilidade de servir de instrumento de libertação, de desmistificação do mundo, contrapondo-se às análises ideológicas conscientes da realidade social na disputa pelo discurso socialmente reconhecido. Entendendo que estas proposições francesas são dominantes na produção brasileira dos últimos anos, primeiro abordaremos como a história imediata foi tratada pela escola dos Annales após 1945, época de seu "ressurgimento", até as proposições mais recentes de autores desta. Em seguida abordaremos a questão da constituição da verdade histórica como resultado do processo de produção de conhecimento histórico e, por fim, iremos abordar a questão da ideologia, das distorções propositais em suas funções políticas e sociais na sociedade de classes.

Palavras-chave: História imediata; verdade histórica; função social da história.

\section{THE STRUGGLES OF IMMEDIATE STORY: FOR WHOM SERVES THE HISTORICAL TRUTH?}

\begin{abstract}
In this article we will discuss some historiographical arguments of French origin, taken as a theoretical and methodological problems, intended to prevent, difficult or limit the analysis of the processes lived by historians, the practice of immediate history. We'll understand these issues through the social and political functions that historical truth (built by a method, an improved theoretical basis and methodological confirmed by historical practice) meets in the social struggles of the present, history as possibility to serve as an instrument of liberation, for demystification of the world, in contrast to the conscious ideological analysis of social reality in the dispute for socially recognized speech. Understanding that these french proposals are dominant in the brazilian productions in recent years, first we'll address how the story was immediately treated by the Annales school after 1945, time of its "resurgence", to the propositions of this most recent authors. Then we will approach the issue of establishment of historical truth as a result of the production process of historical knowledge and, finally, we address the question of ideology, deliberate distortions in their political and social functions in class society.

Keywords: Immediate history, historical truth, the social function of history.
\end{abstract}




\section{INTRODUÇÃO:}

Neste artigo propomos articular a discussão acadêmica sobre a história imediata, cujo relacionamento é feito de receios, recusas e aberturas parciais para a análise dos processos sociais ainda inacabados, e a questão da verdade histórica, da sua validação científica (ou sua recusa) em sua importância social para as lutas do presente. A escolha pelo conceito de história imediata se dá por essa atentar ao tempo histórico como processo social, sendo responsável pelos processos vividos, ainda não acabados. Esta leitura é contraposta com a história do tempo presente que designa seus objetos em relação à distância temporal do pesquisador. Seriam objetos da história do tempo presente acontecimentos, fenômenos e processos que distam do historiador até cerca de vinte ou trinta anos no tempo, enquanto a história próxima daria conta dos mesmos em um recorte de cerca de quarenta ou cinquenta anos de distância ${ }^{2}$. Neste sentido investigaremos como foram constituídas algumas percepções francesas sobre este campo historiográfico, que tornaram-se dominantes na produção histórica brasileira dos últimos anos, buscando alinhar os problemas teóricos e metodológicos que ela supostamente suscita com os limites que expõe na prática daqueles historiadores, prática diretamente relacionada com os projetos históricos e sociais por eles defendidos.

Analisar um objeto cujo desenrolar histórico ocorre na contemporaneidade da pesquisa, de modo algum significa apresentar a vida como ela é, mas sim buscar os motivos pelos quais a vida assim está. Talvez um dos motivos pelos quais esta prática de pesquisa ainda enfrenta uma série de detratores, estes últimos muitas vezes apresentandose como quase coagidos diante do presente, já que foram (e ainda o são) obrigados a revisitar suas posturas e práticas pelo óbvio motivo de que a busca pela compreensão da história vivida não é exclusividade de uma corporação, mas sim de toda humanidade. Mas, uma vez que história apresenta a possibilidade de servir de instrumento de libertação, de desmistificação do mundo, colocando-se ao lado das lutas sociais, pedimos licença para apresentarmos, de modo introdutório, esta discussão.

\section{A HISTÓRIA IMEDIATA NA ACADEMIA:}

A história imediata faz parte do cabedal de possibilidades de análise do historiador a longo tempo, de Heródoto e Tucídides até Jules Michelet e Karl Marx, tendo se tornado alvo de críticas somente no século XIX, no contexto da institucionalização da disciplina, triunfo de determinado projeto de história, vinculado à escola metódica alemã e que generalizou-se como modelo baseando sua peculiaridade científica na cisão entre o passado e o presente - importante naquele momento para a profissionalização da disciplina, já que a afirmou distinta e independente da filosofia e da literatura. Este modelo historiográfico, aproximado das ciências naturais, foi elaborado em universidades da Alemanha por pesquisadores que não foram somente funcionários, mas ideólogos daquele Estado. Ela tornou-se hegemônica por mais de um século, e seus resquícios, mesmo com todos os enfrentamentos que teve até hoje, são facilmente detectáveis. Como comenta Fontana:

Paradoxalmente, estes homens, que se negavam a aceitar a existência de leis históricas gerais acima das realidades nacionais, seriam os criadores de métodos de pesquisa que se difundiriam universalmente até serem admitidos como norma científica da profissão e que seriam considerados, sem fundamento algum, como equivalentes, no campo da história, aos métodos de investigação das ciências da natureza ${ }^{3}$. 
Este modelo só foi aceito sem críticas até o início do século XX, quando diferentes escolas e perspectivas passaram a confrontá-lo. Na França isso ficou a cabo de Émile Durkheim e seguidores como François Simiand, que elaborou talvez o mais contundente ataque à "tribo" dos historiadores e seus "ídolos": o político, o individual e o cronológico. E em outros países as críticas surgiram dos autores que Schaff concebe como representantes de um modelo de processo do conhecimento subjetivo-idealista: Robin George Colingwood na Inglaterra, Benedetto Croce na Itália e Charles Austin Beard e Carl Becker nos Estados Unidos. Estes "presentistas", para além de todas suas falhas e limitações, formularam contraproposições importantes: "- no conhecimento histórico, o sujeito e o objeto constituem uma totalidade orgânica, agindo um sobre o outro e viceversa; - a relação cognitiva nunca é passiva, contemplativa, mas ativa por causa do sujeito que conhece", e por fim que, "o conhecimento e o comprometimento do historiador estão sempre socialmente condicionados; o historiador sempre tem um 'espírito de partido $^{\text {", } 4}$.

E a história imediata, mesmo praticada por diversas correntes não vinculadas à academia, "renasce" no meio historiográfico francês após 1945, constatação de seus próprios críticos, que assinalaram o óbvio: "boa parte do que se leu (e editou) nesse período pelo mundo afora sob o rótulo de 'história' foi, na verdade, algum tipo de história política", , em sua maioria referentes à história imediata (assinalando o boom editorial sobre a Segunda Guerra Mundial neste período). A escola dos Annales se propôs a disputar este nicho do mercado editorial, em que as "suspeitas dos profissionais universitários contrastavam com uma demanda social que cresceria bruscamente nessas últimas décadas", ou seja, admitindo que "o tempo presente era artigo muito vendido nas livrarias, como se impunha nas emissões televisadas que alcançavam altos índices de audiência"6. Neste período a expansão midiática, pontuada na fala de Jean-Pierre Azema, conhece um crescimento acelerado nos países capitalistas centrais, especialmente através do rádio e da televisão, ainda que o interesse pelo imediato não possa ser resumido a impulsos como este, uma vez que "Lissagaray escreve antes da imprensa informativa se desenvolver na França; Trótsky pouco recorre aos recursos radiofônicos [...] e a televisão desempenha um papel secundário na enquete dos dois repórteres-historiadores do 'Washington Post"',7.

É importante lembrar que, no Brasil se produz história próxima, como alguns preferem, desde Francisco Adolfo de Varnhagen, não sendo problemática sua prática até a chegada da percepção francesa. Segundo Ciro Flamarion Cardoso:

O interesse pela História Imediata ou do tempo presente não é assim tão novo! A professora Maria Yedda Linhares, por exemplo, ressalta com razão que tal interesse já norteava em boa medida a Cátedra de História Moderna e Contemporânea que ela dirigia, como catedrática, na Faculdade Nacional de Filosofia da Universidade do Brasil (atualmente, IFCS da UFRJ). Eu mesmo, como estudante de professores dessa cátedra, pesquisei em 1965, no final da graduação de História, ao escolher, na ocasião, especializar-me em História Contemporânea, orientado pelo professor Francisco Falcon, o tema - então candente e ainda em desenvolvimento - da descolonização no ex-Congo belga, com seus múltiplos conflitos e reviravoltas, ligados em boa parte aos interesses e intervenções do capitalismo internacional (e da ONU, a ele vinculada em boa parte) naquela região ${ }^{8}$.

Nos anos 50, indicada por alguns historiadores como o da institucionalização dos Annales na IV seção da École Pratique de Hautes Etudes (Escola Prática de Ensino Superior), financiada em parte pela fundação Rockfeller, suas propostas reafirmaram as 
críticas, já correntes, à história factual. E definindo-se em oposição, apresentaram três proposições: "na primeira apresentam uma definição da história como sendo 'o estudo cientificamente elaborado sobre as diversas atividades e criações dos homens de outros tempos"', deixando claro o enfoque geral em tempos passados, e que Fontana entende como "uma visão tópica que reserva a qualificação de 'científicos' para os métodos de pesquisa, negando-os aos resultados". Por segundo fiam-se em produzir um tipo de história para além da tradicional, que tem como consequência "uma licença para misturar tudo alegremente, sem regras nem prioridades". E em terceiro, defendem "a necessidade de relacionar a história com as ciências sociais próximas e modernizar os métodos de trabalho", que resultaria em "uma retórica sugestiva", mas que possui "características globais de antimétodo"'.

Fernand Braudel assumirá a revista após a morte de Febvre em 1956, tendo como programa um projeto de análise histórica de longa duração, próximo ao estruturalismo e com a manutenção da construção de uma "história total". Neste período a escola irá alçar espaços para além da França, se tornando referência mundial, como alternativa ao marxismo. Novamente, segundo Fontana, "annales é radical no estilo, mas acadêmica na forma e conservadora do ponto de vista político; toca as questões de história econômica e social sem risco de contágio marxista, contando como garantia, com uma equipe de excomunistas reconvertidos"10. E a "nova" história política - que, embora não se confunda com a imediata, possui perspectivas que a aproximam da mesma discussão historiográfica -, afirma um marco nesta década, a defesa da tese de doutorado de René Rémond em 1954 acerca da atuação política das direitas na França ${ }^{11}$. Este "renascimento" do imediato só será plenamente sedimentado em 1978 quando o Centre National de la Recherche Scientifique (Centro Nacional de Pesquisa Científica, CNRS) criou o Institut d'Histoire du Temps Présent (Instituto de História do Tempo Presente, IHTP). Este é parcialmente descendente da Comité d'Histoire de la Deuxième Guerre Mondiale (Comitê de História da Segunda Guerra Mundial), que fora criada em 1951 e cujas fundações remontam a 1944 com a Commission sur l'Histoire de l'Occupation et de la Libération de la France (Comitê sobre a História da Ocupação e da Libertação da França), criado no governo provisório de Charles De Gaulle ${ }^{12}$, durante o mesmo período e processo de institucionalização dos Annales. O domínio de Braudel durou até o maio de 1968, que em sua eclosão trouxe à tona diversos grupos e movimentos intelectuais de contestação ao estabelecido, de revolta contra o sistema, e teve fortes repercussões no meio acadêmico. Seu espírito "carregado de esperanças utópicas, sonhos libertários e surrealistas" ${ }^{13}$, levaram a diferentes práticas sociais:

[...] o movimento revolucionário como festa coletiva e como comunidades humanas livres e igualitárias, a afirmação partilhada da sua subjetividade (sobretudo entres os feministas); a descoberta de novos métodos de criação artística, desde os pôsteres subversivos e irreverentes, até as inscrições poéticas e irônicas nos muros. A reivindicação do direito à subjetividade estava, inseparavelmente, ligada ao impulso anticapitalista radical que atravessava, de um lado ao outro, o espírito de Maio de 68. Esta dimensão não deve ser subestimada: ela permitiu - a frágil aliança entre os estudantes, os diversos grupúsculos marxistas ou libertários e os sindicalistas que organizaram, apesar de suas direções burocráticas, - a maior greve geral da história da França ${ }^{14}$.

E no ano seguinte Braudel e seu grupo foram substituídos por André Burguière, Jacques Le Goff, Marc Ferro, Emanuel Le Roy Ladurie e Jacques Revel ${ }^{15}$, sem grandes 
explicações a não ser a necessidade de integrar novos pesquisadores. Fontana compreende esta mudança como um golpe de estado contra o antigo chefe, não por motivos políticos, mas metodológicos: "Braudel queria manter o rigor do programa globalizante e isto o levara a criticar duramente os trabalhos de pesquisa de Le Roy Ladurie ou de Furet"16, que considerava apenas expressão de uma moda historiográfica. Burguière responderá esta acusação de modo difuso, afirmando a centralidade de se responder às demandas imediatas, mas propositadamente evitando esclarecer como se deram as disputas em torno do projeto de história dominante:

Modismo? Certamente, se o tomarmos como um encaminhamento obrigatório da reflexão ditado pelos problemas e pela lógica da época. Os temas que se situam no centro do debate não excluem outras direções de pesquisa, mas representam o papel de instância de totalização. $O$ campo que definem se torna o que permite explicar a mudança em sua globalidade. Seu avanço corresponde também à influência de uma disciplina provisoriamente dominante no seio das ciências sociais. É o caso da geografia nos anos 30, da economia marxista ou quantitativa no ambiente de reconstrução do pós-guerra, e finalmente da antropologia estrutural a partir dos anos $60^{17}$.

Como visto, esta reação é trazida pelas críticas de 1968, que desnudaram as dificuldades teórico-metodológicas da antiga geração, que indiquemos, centrava-se na mudança de tempos históricos longos, e não nos processos sociais, o que obviamente resultava na recusa de análise do século $\mathrm{XX}$, dos processos vividos (aqui obviamente excetuando as interpretações acerca da Segunda Guerra, escritas ainda no calor do momento por Marc Bloch ${ }^{18}$, ou um pouco depois por Charles Morazé ${ }^{19}$ ). E do mesmo modo foi profundamente criticado o silêncio em relação àqueles que Michelle Perrot chamou de excluídos da história: mulheres, negros, presidiários, operários, etc. Este refluxo não surge somente da óbvia constatação destas lacunas, mas do fato de que havia outros modos de se fazer história, não dominantes na academia francesa, que davam conta destes processos recentes, e já tinham começado a indicar a necessidade de abarcar diferentes temas e objetos. Esta crise teórica (e em boa parte dos casos antiteórica) ficou conhecida como a "crise dos paradigmas das ciências sociais", que propunha uma contraposição à história social, que era atacada como representante de um paradigma economicista, determinista, holístico, estruturalista e erroneamente dito científico ${ }^{20}$. Cardoso pensa politicamente este momento:

Neste sentido, estou de acordo com a observação de Bentley no sentido de serem os anos da década de 1960 (em especial os movimentos sociais de diversos tipos ocorridos em vários países, incluindo o Brasil, em 1968), não um ponto de partida, mas, sim, um final. Foi a partir da década seguinte que tomou forma mais visivelmente, por um lado, uma resposta afirmativa, neoconservadora e neoliberal, por outro, uma resposta "chorosa", negativa - que é o pós-modernismo, não por acaso chamado por alguns de "orfandade de uma geração" [...] - à constatação de que mudanças muito profundas estavam alterando as sociedades humanas. Parece-me evidente que muitos dos elementos de ambas as reações já existiam antes ${ }^{21}$.

E a "volta" do político, da narrativa, da biografia estão vinculadas diretamente com a recusa das bases teóricas totalizantes. Como afirmado na introdução de Por uma história 
política, livro organizado por Rémond, talvez o nome mais referenciado entre os "novos historiadores políticos":

Cada vez menos pesquisadores acham que as infra-estruturas governam superestruturas, e a maioria prefere discernir (como os autores deste livro) uma diversidade de setores - o cultural, o econômico, o social, o político - que se influenciam mútua e desigualmente segundo as conjunturas, guardando ao mesmo tempo cada um sua vida autônoma e seus dinamismos próprios. E também sua especificidade: a política é um lugar de gestão do social e do econômico, mas a recíproca não é verdadeira ${ }^{22}$.

Os motivos apontados como problema para a pesquisa histórica acerca do período imediato, apontados pelas gerações anteriores, e que esta supostamente resolve, soam absurdamente ingênuos se não forem pensados como justificativas para um movimento historiográfico maior, sendo resumidas em duas questões principais: a possibilidade material de produção, no que concerne às fontes e a relação de objetividade do historiador, "quando se tratava de acontecimentos nos quais havíamos estado mais ou menos envolvidos, dos quais havíamos sido testemunhas, observadores, os quais haviam suscitado em nós reações, engajamentos, tomadas de posição",23.

Este movimento de retomada da história imediata dentro da academia francesa não passou impune ao estabelecido, sendo considerado subproduto de um movimento de reação contra a história, seus praticantes acusados de mero interesse editorial e de recusa ao caráter científico da história, filiando hereditariamente sua produção a outras disciplinas, como o jornalismo e a sociologia. Há aqui uma confusão proposital acerca das possibilidades analíticas do historiador, que deixa de se relacionar criticamente com as outras possibilidades de leitura social, e que sem dúvida tem mais a ver com a história do conhecimento do que com a fácil correlação com outro ofício. Obviamente, há um motivo político para tanto: neste caso tem a ver tanto com as disputas dos historiadores franceses por cátedras e financiamento quanto à repercussão destas acusações em disciplinas próximas pela ameaça de "intrusão" da história. "É certo que, na origem, o jornalismo foi o primeiro a chegar ao terreno do presente" 24 , sendo que o que se oculta é a disputa pelo discurso legítimo sobre a realidade social ${ }^{25}$, que não se limita ao campo historiográfico, mas envolve projetos e questões relativas ao todo social. Como segunda filiação alheia à disciplina, teríamos a sociologia, assumindo a presunção que ela se limite ao imediato, com a ideia de uma "sociologia do presente" (discussão que ocorre dentro de determinado projeto de sociologia) trazida por Edgar Morin no mesmo período, em $1969^{26}$. Sobre as justificativas para a recusa do imediato, retornamos a Cardoso:

Outra bobagem que se dizia décadas atrás era que ao historiador compete como objeto o estudo do "passado", sendo o presente a província das ciências sociais. Na verdade, o historiador, a meu ver, estuda as sociedades humanas (passadas ou presentes) no tempo e, por tal razão, traz aos estudos da História Imediata uma perspectiva bem-vinda por ser diferente da dos outros cientistas sociais: em especial, o historiador tem uma sensibilidade maior para o processo de transformação em sua fluidez; não sente tão fortemente a tentação de recortar o tempo em momentos imóveis comparados entre si (em função, por exemplo, de dados dos censos $)^{27}$.

Le Goff faz reflexões consideráveis acerca do papel e das dificuldades que o 
historiador que trabalha com o imediato enfrenta. Ele aponta três grandes diferenças, que resultam em dificuldades, para este tipo de pesquisa histórica. A primeira é em relação aos documentos e fontes, que por um lado podem existir em superabundância, e por outro podem ser inacessíveis - embora o autor observe a possibilidade da história oral a qualifica como "uma das mais frágeis que existem". A segunda seria a implicação pessoal, já que a proximidade com o objeto explicita o engajamento do historiador, o que segundo ele seria, em especial, problema "para a redação da história dos períodos muito recentes nos manuais escolares e em seu ensino". E por fim, a ignorância do futuro, cujo conhecimento a priore permite controlar melhor "o peso do acaso, a liberdade controlada mas real dos homens, as escolhas, a diversidade limitada, mas existente das possibilidades" ${ }^{28}$. Então, traça linhas gerais para a validação da história imediata:

O que espero dos historiadores da difícil história imediata, inclusive dos jornalistas, que, se fizerem bem seu ofício, são verdadeiros historiadores da história imediata, são quatro atitudes: ler o presente, o acontecimento, com profundidade histórica suficiente e pertinente; manifestar quanto a suas fontes o espírito crítico de todos os historiadores segundo os métodos adaptados a suas fontes; não se contentar em descrever e contar, mas esforçar-se para explicar; tentar hierarquizar os fatos, distinguir o incidente do fato significativo, e importante, fazer do acontecimento aquilo que permitirá aos historiadores do passado reconhecê-lo como outro, mas também integrá-lo numa longa duração e numa problemática na qual todos os historiadores de ontem e de hoje, de outrora e do imediato, se reúnam ${ }^{29}$.

Suas proposições são cruciais para dotar a leitura do vivido de senso crítico, cientificamente validável, o que inclusive destoa da maior parte das opiniões presentes no mesmo livro. Mas, quando afirma que "o presente me interessa antes de tudo como cidadão, como homem do presente, mas diante dos acontecimentos, dos fenômenos, dos problemas importantes, minha reação é a de um historiador" ${ }^{\prime 3}$, nota-se a posição conservadora do autor, que separa sua atuação como indivíduo entre duas personas, a do historiador para com o que passou e a de "cidadão" para o que ainda ocorre (para fins de provocação, se Le Goff consegue realizar com sucesso tal cisão, isto incorre em uma óbvia indicação de esquizofrenia no que concerne a sua compreensão do ofício do historiador). Também observa-se a reprodução de alguns mitos, como visto no que refere-se ao ensino de história e a hierarquização dos documentos e fontes, embora validemos plenamente suas proposições acerca do rigor e da compreensão processual do presente. Sobre estas questões Cardoso alega que:

As razões invocadas no passado contra a prática da História Imediata em especial, que é preciso deixar passar algum tempo para que esfriem as paixões e se possa ser "imparcial"; ou que a documentação necessária em parte não esteja acessível para o passado imediato devido a "razões de Estado" - refletiam uma História que acreditava no mito da imparcialidade e dava importância exagerada ou, mais exatamente, unilateral à documentação e às temáticas políticas (estatais, militares, diplomáticas); de qualquer modo, limitada ou não por segredos estatais, a documentação sobre o passado imediato é infinitamente mais rica e variada do que aquela de que possamos dispor, por exemplo, para qualquer período ou assunto de História Antiga, Medieval ou Moderna! Além de ser muito mais fácil para qualquer um de nós entender o passado mais recente do que outro mais antigo, por estar muito mais próximo do 
presente que vivemos em suas características específicas ${ }^{31}$.

Assinalamos novamente que a confluência feita por diversos autores entre história imediata e a imprensa, tem que ser analisada criticamente, afinal, a história imediata não é modalidade analítica de um observatório da imprensa, embora possa se apresentar de tal modo, dado o papel político desempenhado pela mídia, talvez um de seus maiores papeis seja o de desnaturalizar o espaço que ela ocupa, "o mito da não mediação dos meios de comunicação, o qual resulta na transformação instantânea do vivido em História" 32 . Cabendo então ao historiador do imediato:

[...] conferir uma racionalidade histórica ao imprevisível, ao fabuloso: objetiva desnaturalizar o natural (ou seja, apontar que os eventos noticiados estão inseridos num processo histórico, estão vinculados às práticas sociais humanas e são, de certa forma, opções que possuem alternativas) $[\ldots] \mathrm{O}$ historiador possui ferramentas teóricas que lhe proporcionam o distanciamento crítico e a isenção, ao invés da enganadora fórmula constituída pelo distanciamento temporal e pela neutralidade. Neste sentido, o imediato, mesmo com suas peculiaridades deve ser analisado como qualquer outro período histórico ${ }^{33}$.

Novamente, ao assumir posição, o sujeito que escreve história é levado a compreender o passado como campo de disputas, e sua atuação como partícipe da relação de forças políticas e sociais. Como Jean Chesneaux aponta suas conjecturas, hipóteses e conclusões podem "ajudar a colocar problemas, a amadurecê-los. Mas suas informações, suas análises e suas dúvidas só puderam ser formuladas e resgatadas pelo autor porque já circulavam em estado latente", ou seja, "porque eram produzidas por uma prática social" 34 . Nossa prática científica permite sermos objetivos, de maneira alguma idôneos: "a história não faz nada, ela não possui nenhuma imensa riqueza, ela não trava nenhuma batalha. É sobretudo o homem, o homem realmente vivo, que comanda o presente" ${ }^{\text {"35 }}$. Os investigadores abstendo-se de apresentar suas análises, experiências e conclusões sobre os processos vividos abrem espaço para a afirmação de todo tipo de análise ideológica da realidade, formuladas e disseminadas por intelectuais que publicizam distorções conscientes da realidade social, assumindo funções políticas e sociais cruciais para a manutenção do estado das coisas: representar interesses políticos e sociais de um grupo como suposto interesse nacional, buscando elevar as representações, valores e preconceitos de uma classe a caracterizações de caráter universal, trazendo com isto a falsa sensação de serem portadores de um projeto de sociedade particular. Neste sentido, é exigido do historiador consciente de seu lugar de classe e da importância de sua prática social, que avalie, contextualize e denuncie estas proposições. Neste momento abre-se a ruptura definitiva entre os defensores da ordem estabelecida, já que a verdade sempre é revolucionária, a verdade sempre coloca-se ao lado dos dominados.

Entendendo a função política que tal tipo de distorção ideológica conscientemente produzida cumpre, repetimos: não trata-se de "responder" (descendo ao mesmo nível argumentativo) estes ideólogos, mas de formularem-se explicações científicas para sua existência. Nossa honestidade profissional é o motivo pelo qual somos obrigamos a apontar os erros, distorções e deturpações que estes intelectuais disseminam conscientemente através de uma ideologia, e entendendo as funções que esta cumpre na contemporaneidade, entendemos que a verdade histórica de modo algum irá mudar os motivos e modos pelos quais eles mentem. Como já foi dito por Karl Marx, "deixar o erro sem refutação é estimular a imoralidade intelectual"36. E além, pois afirmando as funções 
políticas que seu discurso ideológico cumpre, seria um erro deixar de apontar as distorções históricas e teóricas efetuadas pelo MSM. Isto é parte da função do historiador, arrancar do fetiche a verdade histórica (explicitando seus pressupostos teóricos e metodologicamente como esta é constituída, já que se tem em conta que o "rigor histórico e rigor político se apóiam mutuamente" ${ }^{, 37}$ ), entendendo a quem interessa, as quais grupos sociais servem a busca pela verdade ou a sua dissimulação. Exatamente por isto nem sempre a história mais objetiva é a história mais aceita, porque isto implica em outro sentido que cumpre ao conhecimento histórico: sua função social. A produção do conhecimento não ocorre de maneira autônoma, dissociada da consciência humana, formada, e também formadora, da existência social entre os homens.

\section{A VERDADE HISTÓRICA COMO PROCESSO DE CONHECIMENTO:}

Na produção do conhecimento histórico, como não existe uma relação unilateral ou cindida entre o historiador, o sujeito que pesquisa, e seu objeto, entre estes forma-se uma troca complexa e dialética. Exatamente por isto esta relação não ocorre de modo distante, passivo, mas ativamente: o historiador sofrerá condicionamentos sociais, históricos, técnicos, etc. e sendo um ser ativo nesta realidade social que o condiciona, terá um "espírito de partido",38. Segundo Adam Schaff:

O sujeito que conhece não é um espelho, não é um aparelho registrando passivamente as sensações geradas pelo meio circunvizinho. Pelo contrário, é precisamente o agente que dirige este aparelho, que o orienta, o regula, e em seguida transforma os dados que este lhe fornece. Alguém escreveu muito a propósito que aqueles que comparam o conhecimento à ação de fotografar a realidade esquecem - entre outras coisas - que o aparelho fotográfico registra, e é por isso que uma fotografia nunca é idêntica à outra. $\mathrm{O}$ sujeito que conhece "fotografa" a realidade com a ajuda de um mecanismo específico, socialmente produzido, que dirige a "objetiva" do aparelho. Além disso, "transforma" as informações obtidas segundo o código complicado das determinações sociais que penetram no seu psiquismo mediante a língua em que pensa, pela mediação da sua situação de classe e dos interesses de grupo que a ela se ligam, pela mediação das suas motivações conscientes ou subconscientes e, sobretudo, pela mediação da sua prática social sem a qual o conhecimento é uma ficção especulativa ${ }^{39}$.

Assim, a verdade histórica é uma verdade parcial e objetiva, o que não significa que seja uma meia verdade - já que analisada segundo um método, uma base teórica metodológica aprimorada e confirmada pela prática histórica - mas como já dito, é inevitavelmente uma verdade filtrada pelos condicionamentos históricos, técnicos e sociais de quem a pesquisa. Como o conhecimento é sempre um processo, devido à infinidade da realidade estudada (tanto no sentido da quantidade infinita das relações de cada objeto com outros, como no sentido do desenvolvimento "infinito" da realidade), deste modo à verdade também é processual:

A "verdade" equivale certamente a um "juízo verdadeiro" ou a uma "proposição verdadeira", mas significa também "conhecimento verdadeiro". É neste sentido que a verdade é um devir: acumulando as verdades parciais, o conhecimento acumula o saber, tendendo, num processo infinito, para a verdade total, exaustiva e, neste sentido, 
absoluta $^{40}$.

O conhecimento é o conhecimento de um objeto infinito, na medida em que é infinita a quantidade das suas correlações: o conhecimento é o processo de acumulação das verdades parciais. Neste, e através deste processo, enriquecemos sem cessar o conhecimento. Como dito, se é parcial, então todo conhecimento científico será objetivo e subjetivo: "objetivos em relação ao objeto a que se referem e do qual são o 'reflexo' específico, bem como atendendo ao seu valor universal relativo e à eliminação relativa da sua coloração emotiva; subjetivos, no sentido mais geral, por causa do papel ativo do sujeito que conhece" ${ }^{\text {". }}$. A compreensão sobre este conhecimento "objetivo" precisa ser explicitada, sendo que para Schaff: "é 'objetivo' o que vem do objeto. Neste sentido, entende-se por 'objetivo' o conhecimento que reflete (numa acepção determinada do verbo 'refletir') no espírito que conhece o objeto existindo fora e independentemente deste (ao contrário do conhecimento 'subjetivo' que cria o seu objeto)". Deste modo, "é 'objetivo' o que é válido para todos e não apenas para este ou aquele indivíduo. Portanto, é 'objetivo' o conhecimento que tem um valor universal e não apenas individual (ao contrário do conhecimento 'subjetivo' no sentido de individual)", o que vem a ser "livre de emotividade $e$, portanto, de parcialidade (em oposição com 'subjetivo' no sentido de 'emotivamente colorido' e 'parcial')",42.

Não nos cabe neste artigo adentrarmos exaustivamente no processo de produção do conhecimento histórico, sendo que acredito que uma das melhores sínteses seja de Edward Palmer Thompson através da dialética do conhecimento histórico. É pelo

[...] teste dessas hipóteses face às evidências, o que pode exigir o interrogatório das evidências existentes mas de novas maneiras, ou uma renovada pesquisa para confirmar ou rejeitar as novas noções; a rejeição das hipóteses que não suportam tais provas e o aprimoramento ou revisão daquelas que a suportam, à luz desse ajuste. Na medida em que uma noção é endossada pelas evidências, temos então todo o direito de dizer que ela existe "lá fora", na história real. É claro que não existe realmente, como um plasma que adere aos fatos, ou como um caroço invisível dentro da casca das aparências. O que estamos dizendo é que a noção (conceito, hipótese relativa à causação) foi posta em diálogo disciplinado com as evidências, e mostrou-se operacional; isto é não foi desconfirmada por evidências contrárias, e que organiza com êxito, ou "explica", evidências até então inexplicáveis. Por isto é uma representação adequada (embora aproximativa) da seqüência causal, ou da racionalidade, desses acontecimentos, e conforma-se (dentro da lógica da disciplina histórica) a um processo que de fato ocorreu no passado. Por isto essa noção existe simultaneamente como um conhecimento "verdadeiro", tanto como uma representação adequada de uma propriedade real desses acontecimentos ${ }^{43}$.

Ou seja, o conhecimento histórico resulta da confrontação de um conceito ou hipótese, uma tese (que não resulta de uma tábula rasa, já que confirmando ou confrontando investigações anteriores), com sua antítese, sua determinação objetiva não teórica (os documentos tornados fonte históricas), do que resulta o conhecimento histórico, a síntese.

\section{IDEOLOGIA NA SOCIEDADE DE CLASSES:}

Reafirmando, a prática historiográfica não escapa da própria história, a narrativa 
histórica possui uma função política e ideológica que não está acima das contradições da sociedade de classes. Como sublinhado por Vladimir Ilyitch Uliánov Lênin: "numa sociedade baseada na luta de classes não pode haver ciência social 'imparcial", sendo que "esperar que a ciência fosse imparcial numa sociedade de escravidão assalariada seria uma ingenuidade tão pueril como esperar que os fabricantes sejam imparciais quanto à questão da conveniência de aumentar os salários dos operários diminuindo os lucros do capital" ${ }^{\prime 4}$. Retornando para Marx e Engels:

São os homens os produtores de suas representações, suas ideias, etc., mas os homens reais e atuantes, tal como são condicionados por um determinado desenvolvimento de suas forças produtivas e das relações a eles correspondentes, até chegar às suas mais amplas formações. A consciência nunca pode ser outra coisa que o ser consciente ${ }^{45}$.

A ideologia não se faz mero reflexo mecânico de uma determinada base material, que emergiria como consequência natural de dado desenvolvimento produtivo. A ideologia só pode ser compreendida dentro da análise concreta da luta de classes, não ignorando a necessidade da distinção entre verdade e falsidade, mas que a compreenda além destes marcos, através de sua função e eficácia real para agrupar classes, e frações destas, em posições de domínio e de subordinação. Para tanto iremos novamente recorrer a Gramsci. Ele conceitua ideologia através de duas categorias: a primeira é a das "ideologias historicamente orgânicas, isto é, que são necessárias a uma determinada estrutura", enquanto que "têm uma validade que é validade 'psicológica': elas 'organizam' as massas humanas, formam o terreno no qual os homens se movimentam, adquirem consciência de sua posição, lutam, etc.". E a segunda encarrega-se das "ideologias arbitrárias, racionalísticas, 'voluntaristas", que "não criam mais do que 'movimentos' individuais, polêmicas, etc.". Mesmo atribuindo um lugar menor para estas, ainda afirma que "nem mesmo estas são completamente inúteis, já que funcionam como o erro que se contrapõe à verdade e a afirma"46.

Para Gramsci estas duas distinções são cruciais na distinção do entendimento genérico do conceito: "um elemento de erro na consideração sobre o valor das ideologias, ao que me parece, deve-se ao fato (fato que, ademais, não é casual) de que se dê o nome de ideologia tanto à superestrutura necessária de uma determinada estrutura", assim, "como às elucubrações arbitrárias de determinados indivíduos". Então aponta três pontos desta depreciação: primeiro, "identifica-se a ideologia como sendo distinta da estrutura e afirma-se que não são as ideologias que modificam a estrutura, mas sim vice-versa". No segundo "afirma-se que uma determinada solução política é 'ideológica', isto é, insuficiente para modificar a estrutura, enquanto crê poder modificá-la se afirma que é inútil, estúpida, etc.". Sendo que no terceiro ponto, "passa-se a afirmar que toda ideologia é 'pura' aparência, inútil, estúpida, etc." ${ }^{47}$.

E retorna a Marx e Engels, para assinalar a:

[...] freqüente afirmação de Marx sobre a "solidez das crenças populares" como elemento necessário de uma determinada situação. Ele diz mais ou menos isto: "quando esta maneira de conceber tiver a força das crenças populares", etc. Outra afirmação de Marx é a de que uma persuasão popular tem, com frequência, a mesma energia de uma força material, ou algo semelhante, e que é muito significativa. A análise destas afirmações, creio, conduz ao fortalecimento da concepção de "bloco histórico", no qual, precisamente, as forças materiais são o conteúdo e as ideologias são a forma, distinção entre forma e conteúdo meramente didática, já que as 
forças materiais não seriam historicamente concebíveis sem forma e as ideologias seriam fantasias individuais sem as forças materiais ${ }^{48}$.

Aqui, se faz necessário que se esclareça a conceituação de Gramsci acerca das metáforas de infraestrutura e superestrutura de Marx. Ele as compreende como um bloco histórico, ou seja, uma unidade dialética das instâncias, sendo a "unidade entre a natureza e o espírito (estrutura e superestrutura), unidade dos contrários e dos distintos". Ao que questiona: "pode-se introduzir o critério de distinção também na estrutura? Como se deverá entender a estrutura: como sistema das relações sociais será possível distinguir os elementos 'técnica', 'trabalho', 'classe', etc.", conceitos situados "historicamente e não 'metafisicamente'?"49. Segundo Lúcia Neves e Ronaldo Sant'anna:

Entre estrutura e superestrutura existe, portanto, um nexo necessário e vital. Por isso mesmo, conforme a visão gramsciana - e este é um de seus pontos mais centrais -, as possibilidades de que as superestruturas se constituam em resultante mecânica do que os homens vivenciam no plano estrutural representam uma séria distorção, posto que a articulação entre os planos aponta, inclusive para a possibilidade de que ocorra certa autonomia das relações superestruturais, conforme a conjuntura histórica, as correlações de forças e o grau de organização de uma formação social. Tal fato evidentemente não descarta, mas reforça a mencionada articulação entre os planos, porque essa relação de reciprocidade entre forças materiais e ideologias aponta para uma possibilidade concreta de o desenvolvimento histórico das formações sociais capitalistas ser uma resultante da simultaneidade entre instrumentos de coerção, persuasão das forças político-sociais em disputa pela hegemonia político-social e alterações concretas nas forças materiais de produção social ${ }^{50}$.

Reafirmar esta leitura é crucial, pois como indicado, existem leituras reducionistas e distorcidas da obra de Gramsci, que se tornaram corrente através de autores como Norberto Bobbio, Perry Anderson ou até mesmo de Francisco de Oliveira, em que suas categorias orgânicas são cindidas e até tomadas como antagônicas ${ }^{51}$, seja em relação ao Estado integral ou acerca do bloco histórico. O mesmo tipo de aviso que Gramsci fazia ao apagamento da relação dialética para as metáforas base e superestrutura, que alguns interpretavam em Marx, serve para os que distorcem sua obra: "a pretensão (apresentada como postulado essencial do materialismo histórico) de apresentar e expor qualquer flutuação da política e da ideologia como uma expressão imediata da infra-estrutura deve ser combatida", seja "teoricamente, como um infantilismo primitivo, ou deve ser combatida, praticamente, com o testemunho autêntico de Marx, escritor de obras políticas e históricas concretas" $" 52$. A busca pela verdade histórica serve como oxigenação contra as cristalizações efetuadas contra o marxismo no século passado, cujos exemplos creio ser desnecessário pontuar, e que negaram ao materialismo histórico e dialético seu caráter de metodologia para a análise da realidade social e sua superação.

\section{REFERÊNCIAS FINAIS:}

Para nós é claro que as dificuldades e problemas que a história imediata supostamente suscita têm muito mais a ver com projetos conservadores de história (e de sociedade) do que necessariamente com dificuldades teórico-metodológicas intrínsecas. E que mesmo quando a academia fora obrigada a incluir sob seus domínios o terreno do imediato, para afirmar a "profissionalização" da escrita da história vivida, ou dito de outro 
modo, para garantir o controle corporativo sobre esta produção, estes projetos conservadores foram obrigados a "aprimorar-se", ampliando seus horizontes, mas sem alterar seu cerne. A história imediata explicita a disputa pelo discurso socialmente aceito, insere a leitura científica (mas não a rebaixa) no terreno das disputas ideológicas, como parte constitutiva da guerra de posições no campo político, em embates que perpassam o corpo social, através da luta de classes. Deste modo, o rigor histórico, a honestidade profissional, a luta pela verdade histórica, só podem estar ao lado das lutas pela libertação.

\section{Referências}

AZEMA, J-P. “Tempo presente” (verbete). In. BURGUIÈRE, A. (org.). Dicionário das ciências históricas. Rio de Janeiro: Imago, 1993.

BARROS, C. Para um novo paradigma historiográfico. Disponível em http://www.hdebate.com/cbarros/spanish/articulos/nuevo_paradigma/hacia/tempo.htm, acessado em 10.09.10.

BIANCHI, A. O laboratório de Gramsci: filosofia, história e política. São Paulo: Alameda, 2008.

BLOCH, M. A estranha derrota. Rio de Janeiro: Jorge Zahar, 2011.

BURGUIÈRE, A. “Anais (escola dos)” (verbete). In. BURGUIÈRE, A. (org.). Dicionário das ciências históricas. Rio de Janeiro: Imago, 1993.

CARDOSO, C. F. Um historiador fala de teoria e metodologia. Bauru: EDUSC, 2005.

CHAVEAU, A.; TÉTARD, P. "Questões para a história do presente”. In. CHAVEAU, A.; TÉTARD, P. (orgs.). Questões para a história do presente. Bauru: EDUSC, 1999.

CHESNEAUX, J. Devemos fazer tábula rasa do passado? Sobre a história e os historiadores. São Paulo: Ática, 1995.

FALCON, F. "História e poder". In. CARDOSO, C. F.; VAINFAS, R. (orgs.). Domínios da história: ensaios de teoria e metodologia. Rio de Janeiro: Campus, 1997.

FONTANA, J. A história dos homens. Bauru: EDUSC, 2004.

GRAMSCI, A. Cadernos do cárcere. Volume 1. Rio de Janeiro: Civilização Brasileira, 1999.

GRAMSCI, A. Cadernos do cárcere. Volume 3. Rio de Janeiro: Civilização Brasileira, 2002.

HISTÓRIA AGORA. "Entrevista com o professor Ciro Flamarion Cardoso (19.03.07)".

História Agora. $\mathrm{n}^{\circ}$. 1. Disponível em

http://www.historiagora.com/index.php?option=com_content\&task=view\&id=10\&Itemid= 30, acessado em 10.09.10.

INSTITUT D'HISTOIRE DU TEMPS PRÉSENT. Historique. Disponível em http://www.ihtp.cnrs.fr/spip.php\%3Frubrique1\&lang=fr.html, acessado em 13.09.10.

LACOUTURE, J. “A história imediata”. In. LE GOFF, J.; CHARTIER, R.; REVEL, J. (orgs.). A história nova. São Paulo: Martins Fontes, 1998.

LE GOFF, J. “A história nova”. In. LE GOFF, J.; CHARTIER, R.; REVEL, J. (orgs.). A 
história nova. São Paulo: Martins Fontes, 1998.

LE GOFF, J. "A visão dos outros: um medievalista diante do presente". In. CHAVEAU, A.; TÉTART, P. (orgs.). Questões para a história do presente. Bauru: EDUSC, 1999.

LÊNIN, V. I. As três partes e as três fontes constitutivas do marxismo. Disponível em http://files.agb-recife.webnode.com.br/200000028-

b54e4b649e/As\%20Tr\%C3\%AAs\%20Fontes\%20e\%20as\%20Tr\%C3\%AAs\%20partes\%20

Constitutivas\%20do\%20Marxismo\%20(Lenin).pdf, acessado em 14.10.11.

LÖWY, M. "O romantismo revolucionário de maio 68". Espaço Acadêmico. n”. 84.

Disponível em http://www.espacoacademico.com.br/084/84esp_lowyp.htm, acessado em 10.08.10.

MARX, K.; ENGELS, F. A ideologia alemã. São Paulo: Martin Claret, 2004.

MORAZÉ, C. A lógica da história. São Paulo: Difusão Européia do Livro, 1970.

NEVES, L. M. W.; SANT'ANNA R. "Introdução: Gramsci, o Estado educador e a nova pedagogia da hegemonia". In. NEVES, L. M. W. A nova pedagogia da hegemonia: estratégias do capital para educar o consenso. São Paulo: Xamã, 2005.

PAILLARD, B. "Imediata (história)" (verbete). In. BURGUIÈRE, A. (org.). Dicionário das ciências históricas. Rio de Janeiro: Imago, 1993.

RÉMOND, R. "Introdução". In. RÉMOND, R. (org.). Por uma história política. Rio de Janeiro: FGV, 2003.

RÉMOND, R. Por que a história política? Disponível em http://virtualbib.fgv.br/ojs/index.php/reh/article/viewArticle/1975, acessado em 10.09.10.

RODRIGUES, G. "História: uma ciência do presente". In. FERNANDEZ, E. P. F.; PADRÓS, E. S.; RIBEIRO, L. D. T.; GORKON, C. Van. Contrapontos - Ensaios de história imediata. Porto Alegre: Folha da história/Palmares, 1999.

SCHAFF, A. História e verdade. São Paulo: Martins Fontes, 1991.

THOMPSON, E. P. Miséria da teoria: ou um planetário de erros. Sem editora, 2009.

\section{Notas}

\footnotetext{
${ }^{1}$ Bacharel em História/UEPG. Mestre em História/UNIOESTE. Linha Estado e Poder. Este artigo faz parte da dissertação "Os litores da nossa burguesia: o Mídia Sem Máscara em atuação partidária (2002-2011)", orientada pelo Dr. Gilberto Grassi Calil e financiada pela Fundação Araucária. E-mail: lucas.patschiki@gmail.com.

${ }^{2}$ Estas perspectivas são defendidas em CHAVEAU, A.; TÉTARD, P. "Questões para a história do presente". In. CHAVEAU, A.; TÉTARD, P. (orgs.). Questões para a história do presente. Bauru: EDUSC, 1999. p. 27.

${ }^{3}$ FONTANA, J. A história dos homens. Bauru: EDUSC, 2004. p. 231.

${ }^{4}$ SCHAFF, A. História e verdade. São Paulo: Martins Fontes, 1991. p. 105.

${ }^{5}$ FALCON, F. "História e poder". In. CARDOSO, C. F.; VAINFAS, R. (orgs.). Domínios da história: ensaios de teoria e metodologia. Rio de Janeiro: Campus, 1997. p. 70.

${ }^{6}$ AZEMA, J-P. "Tempo presente” (verbete). In. BURGUIÈRE, A. (org.). Dicionário das ciências históricas. Rio de Janeiro: Imago, 1993. p. 741. Duby reconhece que o retorno do político, do acontecimento, da
} 
biografia e da narrativa se deram pela expectativa do público. DUBY, G. "L'histoire continue". Paris: Odile Jacob, 1991. p. 150-152. apud FONTANA, J. A história dos homens. op. cit. p. 395.

${ }^{7}$ LACOUTURE, J. "A história imediata”. In. LE GOFF, J.; CHARTIER, R.; REVEL, J. (orgs.). A história nova. São Paulo: Martins Fontes, 1998. p. 227. Refere-se ao escândalo político conhecido como "Watergate", onde os jornalistas Bob Woodward e Carl Bernstein do Washington Post conseguiram comprovar a ligação do presidente republicano Richard Nixon com o assalto à sede do Partido Democrata em Washington em 1972, durante a campanha que o reelegeu. Esta reportagem, que Lacouture utiliza como exemplo de história imediata praticada por jornalistas, abriu caminho para a renúncia de Nixon em 1974.

${ }^{8}$ HISTÓRIA AGORA. "Entrevista com o professor Ciro Flamarion Cardoso (19.03.07)". História Agora. $\mathrm{n}^{\circ}$. 1. Disponível em http://www.historiagora.com/index.php?option=com_content\&task=view\&id=10\&Itemid=30, acessado em 10.09.10.

${ }^{9}$ FONTANA, J. A história dos homens. op. cit. p. 273-274.

${ }^{10}$ Idem. p. 278.

${ }^{11}$ BURGUIÈRE, A. “Anais (escola dos)” (verbete). In. BURGUIÈRE, A. (org.). Dicionário das ciências históricas. op. cit. p. 50.

${ }^{12}$ INSTITUT D'HISTOIRE DU TEMPS PRÉSENT. Historique. Disponível em http://www.ihtp.cnrs.fr/spip.php\%3Frubrique1\&lang=fr.html, acessado em 13.09.10.

${ }^{13}$ LÖWY, M. "O romantismo revolucionário de maio 68". Espaço Acadêmico. n’. 84. Disponível em http://www.espacoacademico.com.br/084/84esp_lowyp.htm, acessado em 10.08.10.

${ }^{14}$ Idem.

${ }^{15}$ LE GOFF, J. “A história nova”. In. LE GOFF, J.; CHARTIER, R.; REVEL, J. (orgs.). A história nova. op. cit. p. 37.

${ }^{16}$ FONTANA, J. A história dos homens. op. cit. p. 279.

${ }^{17}$ BURGUIÈRE, A. “Anais (escola dos)" (verbete) In. BURGUIÈRE, A. (org.). Dicionário das ciências históricas. op. cit. p. 52. Grifos nossos.

${ }^{18} \mathrm{BLOCH}$, M. A estranha derrota. Rio de Janeiro: Jorge Zahar, 2011.

${ }^{19}$ MORAZÉ, C. A lógica da história. São Paulo: Difusão Européia do Livro, 1970.

${ }^{20}$ BARROS, C. Para um novo paradigma historiográfico. Disponível em http://www.hdebate.com/cbarros/spanish/articulos/nuevo_paradigma/hacia/tempo.htm, acessado em 10.09.10.

${ }^{21}$ CARDOSO, C. F. Um historiador fala de teoria e metodologia. Bauru: EDUSC, 2005. p. 164-165.

${ }^{22}$ RÉMOND, R. "Introdução". In. RÉMOND, R. (org.). Por uma história política. Rio de Janeiro: FGV, 2003. p. 10. Grifos nossos.

${ }^{23}$ RÉMOND, R. Por que a história política? Disponível em http://virtualbib.fgv.br/ojs/index.php/reh/article/viewArticle/1975, acessado em 10.09.10.

${ }^{24}$ PAILlARD, B. "Imediata (história)" (verbete). In. BURGUIÈRE, A. (org.). Dicionário das ciências históricas. op. cit. p. 409.

${ }^{25}$ LACOUTURE, J. “A história imediata”. In. LE GOFF, J.; CHARTIER, R.; REVEL, J. (orgs.). A história nova. op. cit. p. 219.

${ }^{26}$ PAILLARD, B. "Imediata (história)" (verbete). In. BURGUIÈRE, A. (org.). Dicionário das ciências históricas. op cit. p. 408.

${ }^{27}$ HISTÓRIA AGORA. "Entrevista com o professor Ciro Flamarion Cardoso (19.03.07)”. História Agora. $\mathrm{n}^{\text {o. }}$ 1. op. cit.

${ }^{28}$ LE GOFF, J. “A visão dos outros: um medievalista diante do presente”. In. CHAVEAU, A.; TÉTART, P. (orgs.). Questóes para a história do presente. op. cit. p. 100-101.

${ }^{29}$ Idem. p. 101-102. 


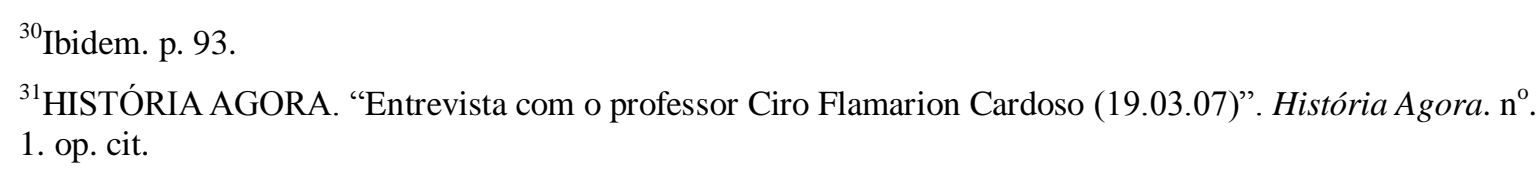

${ }^{32}$ RODRIGUES, G. "História: uma ciência do presente". In. FERNANDEZ, E. P. F.; PADRÓS, E. S.; RIBEIRO, L. D. T.; GORKON, C. Van. Contrapontos - Ensaios de história imediata. Porto Alegre: Folha da história/Palmares, 1999. p. 16.

${ }^{33}$ Idem. p. 17-18.

${ }^{34}$ CHESNEAUX, J. Devemos fazer tábula rasa do passado? Sobre a história e os historiadores. São Paulo: Ática, 1995. p. 17.

${ }^{35}$ Idem. p. 22.

${ }^{36}$ MARX, K. apud THOMPSON, E. P. Miséria da teoria: ou um planetário de erros. Sem editora, 2009. p. 6.

${ }^{37}$ CHESNEAUX, J. Devemos fazer tábula rasa do passado? Sobre a história e os historiadores. op. cit. p. 62.

${ }^{38} \mathrm{SCHAFF}$, A. História e verdade. op. cit. p. 105.

${ }^{39}$ Idem. p. 81.

${ }^{40}$ Ibidem. p. 98.

${ }^{41}$ Ibidem. p. 89.

${ }^{42}$ Ibidem. p. $87-88$.

${ }^{43}$ THOMPSON, E. P. Miséria da teoria: ou um planetário de erros. op. cit. p. 63-64.

${ }^{44} \mathrm{LÊNIN}, \mathrm{V}$. I. As três partes e as três fontes constitutivas do marxismo. Disponível em http://files.agbrecife.webnode.com.br/200000028-

b54e4b649e/As\%20Tr\%C3\%AAs\%20Fontes\%20e\%20as\%20Tr\%C3\%AAs\%20partes\%20Constitutivas\%20 do\%20Marxismo\%20(Lenin).pdf, acessado em 14.10.11.

${ }^{45}$ MARX, K.; ENGELS, F. A ideologia alemã. São Paulo: Martin Claret, 2004. p. 51.

${ }^{46}$ GRAMSCI, A. Cadernos do cárcere. Volume 1.Rio de Janeiro: Civilização Brasileira, 1999. p. 237-238.

${ }^{47}$ Idem. p. $237-238$.

${ }^{48}$ Ibidem. p. 238.

${ }^{49}$ GRAMSCI, A. Cadernos do cárcere. Volume 3. Rio de Janeiro: Civilização Brasileira, 2002. p. 26-27.

${ }^{50}$ NEVES, L. M. W.; SANT'ANNA R. "Introdução: Gramsci, o Estado educador e a nova pedagogia da hegemonia". In. NEVES, L. M. W. A nova pedagogia da hegemonia: estratégias do capital para educar o consenso. São Paulo: Xamã, 2005. p. 21.

${ }^{51}$ BIANCHI, A. O laboratório de Gramsci: filosofia, história e política. São Paulo: Alameda, 2008. p. 173.

${ }^{52}$ GRAMSCI, A. Cadernos do cárcere. Volume 1. op. cit. p. 238.

Recebido em maio/2012

Aprovado em novembro/2012 